\title{
Fluxo difusivo de potássio em solos sob diferentes níveis de umidade e de compactação
}

\author{
José P. V. da Costa ${ }^{1}$, Nairam F. de Barros ${ }^{2}$, Adelmo L. Bastos ${ }^{1}$ \& Abel W. de Albuquerque ${ }^{1}$
}

\begin{abstract}
RESUMO
O potássio, à semelhança do fósforo, é transportado por difusão até a zona de absorção. Oito níveis de umidade (10, 20, 40, 60, 70, 80, 90 e 100\%), definidos em função da porosidade total, foram combinados com dois níveis de densidade do solo (natural e 30\% deste valor) em três tipos de solo. Como unidade experimental se utilizaram anéis de PVC, que serviram como câmara de difusão, com $5 \mathrm{~cm}$ de altura e $10 \mathrm{~cm}$ de diâmetro interno. Para avaliação do fluxo difusivo do potássio no solo, lâminas de resina de troca catiônica foram colocadas horizontalmente na superfície das amostras de solo, nas câmaras de difusão. O trabalho foi conduzido em condições de laboratório com temperatura controlada a $25 \pm 3{ }^{\circ} \mathrm{C}$ durante 15 dias; após este período, as lâminas foram retiradas e lavadas com jato de água e o potássio adsor-

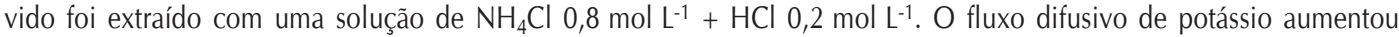
com os níveis de umidade e diminuiu com a compactação. Com a compactação do solo, observou-se uma relação linear entre os níveis de umidade e a difusão de potássio, mas para os solos não compactados esta relação somente foi observada para o solo mais arenoso; assim, a relação direta entre o fluxo difusivo de potássio e o conteúdo de umidade do solo não é universal, como previsto pela equação de difusão.
\end{abstract}

Palavras-chave: água, densidade do solo, difusão de nutriente

\section{Influence of water content and soil compaction on the potassium diffusion flow into soil}

\begin{abstract}
Potassium, as well as phosphorus, is transported by diffusion to the absortion zone. Eight levels of soil moisture (10, 20, $40,60,70,80,90$ and $100 \%$ ), defined as a percentage of the soil total porosity, were combined with two soil densities (the natural bulk density and a compaction corresponding to 30\% above the natural bulk density) in three soil samples, varying in their physiochemical characteristics, and the potassium diffusive flux (KDF) was measured using resin strips. To determine KDF, the resin strips were placed on the top of the soil samples. Chambers made of PVC rings $(10 \mathrm{~cm}$ in diameter and $5 \mathrm{~cm}$ high) were used, which were placed in plastic bags to avoid evaporation, and maintained under controlled temperature $\left(25 \pm 3{ }^{\circ} \mathrm{C}\right)$ for 15 days. After this period of time the resin strips were removed, washed with destilled water, and $\mathrm{K}$ extracted by a $\mathrm{NH}_{4} \mathrm{Cl} 0.8 \mathrm{~mol} \mathrm{~L}^{-1}+\mathrm{HCl} 0.2 \mathrm{~mol} \mathrm{~L}^{-1}$ solution. $\mathrm{KDF}$ increased with soil moisture levels and decreased with compaction. When the soil was compacted, a linear relation between moisture levels and KDF was observed. However, for non-compacted soils, this relation was observed only for the sandy soil, not for the more clayey ones. It was concluded that the linear relation between KDF and soil moisture content, as predicted by the diffusion equation, is not universal and depends upon the range of soil moistures under consideration.
\end{abstract}

Key words: water, bulk density, nutrient diffusion

CECA/UFAL. BR 104 Norte, Km 85. CEP 57100-000, Rio Largo, AL. Fone: (82) 261-1351. E-mail: jpvc@fapeal.br; adelmo-bastos@bol.com.br; awa@fapeal.br

Departamento de Solos/UFV. CEP 36571-000, Viçosa, MG. Fone: (31) 899-2471. E-mail: nfbarros@mail.ufv.br 


\section{INTRODUÇÃO}

A ligação aos minerais sob diferentes forças, permite a adoção de vários critérios para classificar o potássio do solo. Tisdale \& Nelson (1975), segundo um critério de disponibilidade para as plantas, classificam o potássio do solo em: relativamente indisponível, lentamente disponível e prontamente disponível. Ritchey (1982), conforme um critério mais químico, o classifica em potássio estrutural, potássio temporariamente fixado entre as camadas de argilas 2:1, potássio trocável e potássio presente na solução do solo.

A forma trocável pode também ser expressa em relação à sua percentagem na CTC, denominada saturação por potássio, que pode ser utilizada para explicar respostas à adubação potássica, em certos casos melhor que apenas o valor absoluto de K-trocável (Lopes, 1984; Bortoluzzi et al., 2005).

O potássio apresenta, em solos de regiões de clima tropical, comportamento aparentemente mais simples do que aquele em solos de regiões de clima temperado. Nos solos com predominância de matéria orgânica, caulinita e óxidos de ferro e de alumínio como materiais responsáveis pela capacidade de troca de cátions, o potássio trocável representa o teor disponível do elemento; nos solos de regiões de clima temperado este teor é dependente do potássio nãotrocável e existem minerais que fixam o elemento entre suas camadas.

No que concerne ao mecanismo de suprimento às raízes, o potássio mostra semelhança com o fósforo pelo fato de ambos serem transportados por difusão até a zona de absorção; no entanto, o teor de potássio na solução do solo pode atingir concentrações elevadas, conferindo-lhe maior mobilidade em relação ao fósforo.

Barber (1974) se refere à difusão como o principal mecanismo de transporte do potássio da solução do solo para as raízes das plantas, responsável por $86 \%$ do seu suprimento, com o fluxo de massa e a intercepção radicular representando 11 e 3\%, respectivamente. No Brasil, trabalhando com diferentes solos do Rio Grande do Sul, Vargas (1982) verificou que o mecanismo de difusão contribuiu com 72 a 95\% do provimento de potássio para a cultura do milho. Ruiz (1999), Rosolém et al. (2003) e Fernandes (2006) também constataram que a difusão foi o principal mecanismo de suprimento de $K$ às raízes de plantas.

O aumento do conteúdo volumétrico de água no solo reduz a tortuosidade do caminho de difusão; este aumento na espessura do filme de água no interior dos poros aumenta o fator de impedância e, conseqüentemente, o fluxo difusivo; a difusão e a absorção de potássio são favorecidas pela manutenção de alta concentração deste nutriente na solução do solo e pela ausência de impedimentos físico e químico.

Um dos problemas que vêm sendo motivo de preocupação de pesquisadores é a compactação do solo. Os danos causados pelo fenômeno são bem conhecidos, uma vez que afetam significativamente e de maneira negativa, o crescimento e o desenvolvimento das plantas (Beutler et al., 2006).

A qualidade da porosidade do solo afeta negativamente a disponibilidade de nutrientes para as plantas, visto que os mecanismos de fluxo de massa e difusão, responsáveis pelo transporte de nutrientes até as raízes, são processos dependentes da estrutura do solo; além de alterar os mecanismos pelos quais os nutrientes são transportados no solo, a compactação também pode afetar a quantidade de nutrientes disponíveis (Medeiros et al., 2005).

Alterações na densidade do solo afetam a tortuosidade da trajetória seguida do elemento transportado. De acordo com Warncke \& Barber (1972a), provavelmente a difusão aumenta com o aumento da densidade do solo até determinado valor, diminuindo rapidamente com novos acréscimos. Esses autores observaram, ainda, que a tortuosidade foi reduzida com o aumento da densidade e a redução do comprimento do caminho da difusão do elemento, porém com densidade superior a $1,3 \mathrm{~g} \mathrm{~cm}^{-3}$, as partículas sólidas começaram a tornar este caminho mais tortuoso.

Sempre que o solo seca, diminui a difusão do potássio (Oliveira et al., 2004). O coeficiente de difusão varia com o conteúdo volumétrico de água e, quanto mais seco estiver o solo mais tortuoso será o caminho da difusão. Em água pura o fator de impedância $\left(\mathrm{f}_{1}\right)$ é igual a 1 ; em solo saturado, aproximadamente 0,4 ; na capacidade de campo, em torno de 0,2 e, próximo ao ponto de murcha, aproximadamente 0,01 (Wild, 1981). Mehta et al. (1995) consideram a impedância unitária no caso de solos arenosos com elevada umidade em que a influência das partículas de argila é muito pequena.

Propôs-se, neste trabalho, avaliar o fluxo difusivo de potássio em três solos de texturas distintas, quando submetidos a diferentes níveis de umidade e a compactação, utilizando-se resina de troca catiônica como dreno.

\section{MATERIAL E MÉTODOS}

\section{Caracterização dos solos}

O ensaio foi desenvolvido em laboratório utilizando-se amostras da camada de 0-20 cm de profundidade de três solos do Estado de Minas Gerais (EMBRAPA, 1999): Latossolo Vermelho textura média $\left(\mathrm{LV}_{1}\right)$ - Três Marias, Latossolo Vermelho Distroférrico, textura argilosa (LVdf) - São Sebastião do Paraíso e Latossolo Vermelho textura muito argilosa $\left(\mathrm{LV}_{2}\right)$ - Sete Lagoas. As amostras foram secadas ao ar, destorroadas, passadas em peneira de malha de $2 \mathrm{~mm}$ de abertura e homogeneizadas, retirando-se-lhes subamostras, para caracterização física, química e mineralógica (Tabela 1 e Figura 1).

\section{Montagem do experimento}

$\mathrm{O}$ ensaio consistiu do arranjo fatorial $3 \times 8 \times 2$ correspondendo, respectivamente, a três tipos de solo, oito níveis de umidade e dois níveis de compactação. Para avaliação do efeito da compactação consideraram-se a densidade natural do solo e um acréscimo de $30 \%$ neste valor, por meio de compressão das amostras dos solos, diminuindo-se o seu volume até atingir a densidade desejada. Os tratamentos, com quatro repetições, foram dispostos em blocos casualizados. Como unidade experimental se usaram anéis de PVC com $5 \mathrm{~cm}$ de altura e 10 cm de diâmetro (Figura 2), que serviram como câmara de 
Tabela 1. Atributos químicos e físicos dos solos estudados

\begin{tabular}{|c|c|c|c|}
\hline Atributo & $\mathrm{LV}_{1}$ & LVdf & $\mathrm{LV}_{2}$ \\
\hline pH em $\mathrm{H}_{2} \mathrm{O}(1: 2,5)$ & 5,40 & 4,70 & 4,70 \\
\hline pH em KCI $(1: 2,5)$ & 4,20 & 4,10 & 4,00 \\
\hline $\mathrm{Al}^{3+}\left(\mathrm{cmol}_{\mathrm{c}} \mathrm{dm}_{-3}\right)^{1 /}$ & 0,75 & 0,54 & 1,22 \\
\hline $\mathrm{Ca}^{2+}\left(\mathrm{cmol}_{\mathrm{c}} \mathrm{dm}^{-3}\right)^{1 /}$ & 0,05 & 0,50 & 0,94 \\
\hline $\mathrm{Mg}^{2+}\left(\mathrm{cmol}_{\mathrm{c}} \mathrm{dm}^{-3}\right)^{1 /}$ & 0,04 & 0,20 & 0,21 \\
\hline $\mathrm{H}+\mathrm{Al}\left(\mathrm{cmol}_{\mathrm{c}} \mathrm{dm}^{-3}\right)^{2 /}$ & 3,89 & 7,20 & 14,54 \\
\hline$P\left(m g ~ d m^{-3}\right)^{3 /}$ & 0,70 & 1,90 & 1,30 \\
\hline $\left.\mathrm{K}(\mathrm{mg} \mathrm{dm})^{-3}\right)^{3 /}$ & 10,00 & 20,00 & 23,00 \\
\hline Carbono orgânico (dag kg-1 $)^{4 /}$ & 0,53 & 1,70 & 2,13 \\
\hline CTC efetiva $\left(\mathrm{cmol}_{\mathrm{C}} \mathrm{kg}^{-1}\right)$ & 0,87 & 1,29 & 2,37 \\
\hline CTC total $\left(\mathrm{cmol}_{\mathrm{c}} \mathrm{kg}^{-1}\right)$ & 4,01 & 7,95 & 15,75 \\
\hline $\mathrm{m}(\%)^{5 /}$ & 86,20 & 41,90 & 51,50 \\
\hline Capacidade de campo $\left(\text { dag } \mathrm{kg}^{-1}\right)^{6 /}$ & 15,40 & 26,00 & 36,70 \\
\hline Areia grossa $\left(\text { dag } \mathrm{kg}^{-1}\right)^{7 /}$ & 32,00 & 6,00 & 9,00 \\
\hline Areia fina $\left(\text { dag } \mathrm{kg}^{-1}\right)^{7 /}$ & 51,00 & 25,00 & 5,00 \\
\hline Silte $\left(\text { dag } \mathrm{kg}^{-1}\right)^{7 /}$ & 4,00 & 23,00 & 10,00 \\
\hline Argila $\left(\text { dag } \mathrm{kg}^{-1}\right)^{7 /}$ & 13,00 & 49,00 & 76,00 \\
\hline Densidade do solo $\left(\mathrm{g} \mathrm{cm}^{-3}\right)^{8 /}$ & 1,38 & 1,22 & 1,00 \\
\hline Densidade de partículas $\left(\mathrm{g} \mathrm{cm}^{-3}\right)^{9 /}$ & 2,63 & 3,03 & 2,63 \\
\hline Porosidade (\%) & 48,00 & 60,00 & 62,00 \\
\hline
\end{tabular}

1/ KCl 1 mol L-1 (Vettori, 1969); ${ }^{2 /}$ Extrator CaOAc 0,5 mol L-1, pH 7,0 (Defelipo \& Ribeiro, 1981); ${ }^{3 /}$ Extrator Mehlich-1; ${ }^{4 /}$ Método Walkley e Black (Jackson, 1958); ${ }^{5 /}$ Saturação por alumínio; 6/ Método da coluna (Fernandes, 1967); ${ }^{7 /}$ (EMBRAPA, 1997); ${ }^{8 /}$ Método da proveta (EMBRAPA, 1997); 9/ Método do balão volumétrico (EMBRAPA, 1997)

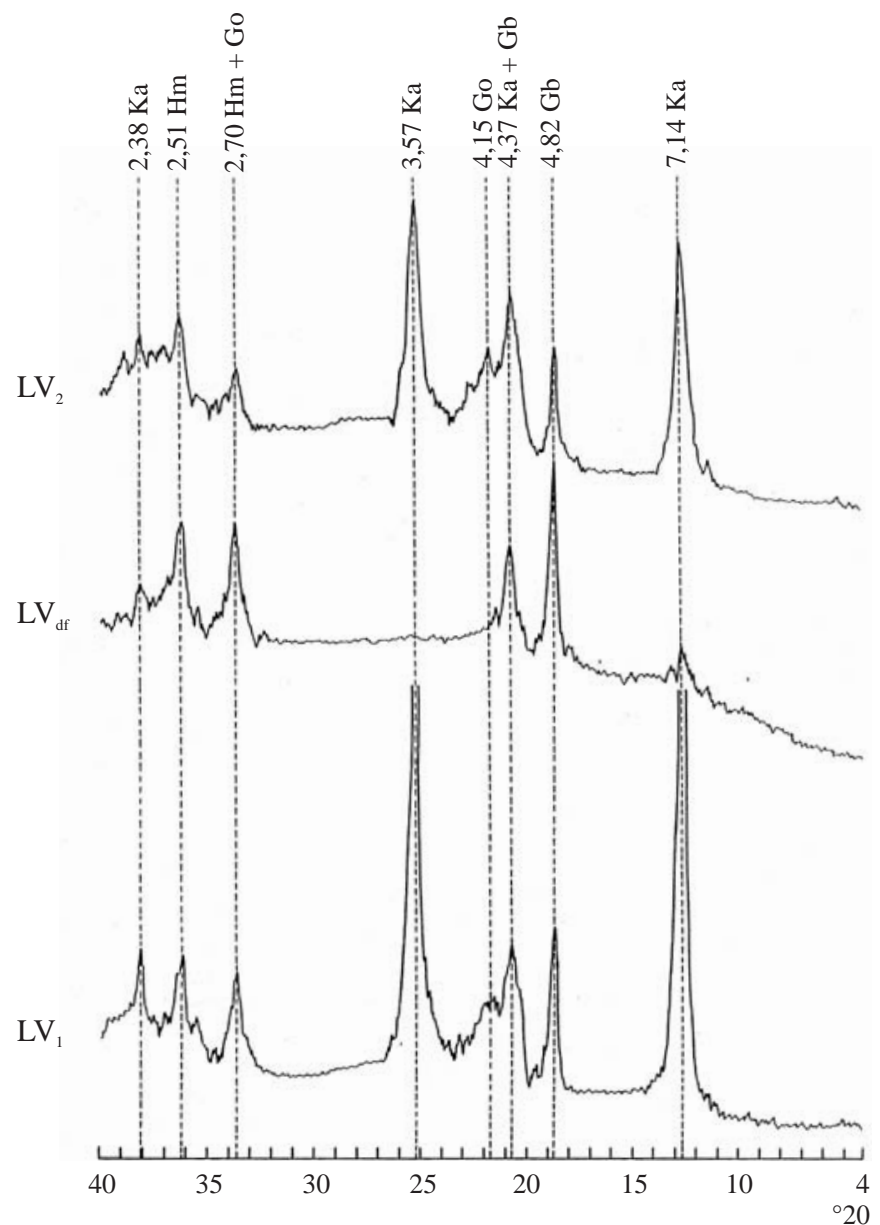

Radiação Cu - K $\alpha$. Ka - caulinita; Hm - hematita; Go - goethita; Gb - gibbsita

$\mathrm{LV}_{1}$ - Latossolo Vermelho textura média; LVdf - Latossolo Vermelho distroférrico, textura argilosa; $\mathrm{LV}_{2}$ - Latossolo Vermelho textura muito argilosa

Figura 1. Difratogramas de raios-X da fração argila em lâminas orientadas de amostras dos solos estudados difusão (Villani, 1995), com volume útil de $360 \mathrm{~cm}^{3}$ para as amostras com densidade do solo normal e $277 \mathrm{~cm}^{3}$ para as amostras de solo compactadas.

Os anéis de PVC tiveram o fundo fechado com lâmina de isopor de 1,2 cm de espessura, fixada com fita de polietileno; após receberem os tratamentos, foram cobertos com plástico para evitar perda de umidade. Os níveis de umidade utilizados corresponderam a 10, 20, 40, 60, 70, 80, 90 e $100 \%$ da porosidade total para os três solos em condições naturais e quando submetidos a compactação (Tabela 2). Para os tratamentos com níveis elevados de umidade sentiu-se necessidade da vedação do anel com isopor, utilizando-se cola para evitar vazamento de água.

A dose de potássio foi definida de modo que o teor deste elemento nos solos fosse elevado para $40 \%$ da CTC. O potássio foi aplicado em solução utilizando-se, como fonte, o fosfato monobásico de potássio $\left(\mathrm{KH}_{2} \mathrm{PO}_{4}\right)$; após secagem, os solos foram destorroados e novamente passados em peneira de malha de $2 \mathrm{~mm}$ de abertura e promovida sua

Tabela 2. Conteúdos de água aplicados nos solos utilizados em condições de densidade natural e compactados

\begin{tabular}{|c|c|c|c|c|c|c|}
\hline \multirow{3}{*}{$\begin{array}{c}\text { Nível de } \\
\text { umidade }^{1 /} \\
\%\end{array}$} & \multicolumn{2}{|c|}{$\mathrm{LV}_{1}$} & \multicolumn{2}{|c|}{$\mathrm{LV}_{\mathrm{df}}$} & \multicolumn{2}{|c|}{$\mathrm{LV}_{2}$} \\
\hline & Natural & Compact. & Natural & Compact. & Natural & Compact. \\
\hline & \multicolumn{6}{|c|}{$\mathrm{cm}^{3} \mathrm{~cm}^{-3}$} \\
\hline 10 & 0,048 & 0,032 & 0,060 & 0,047 & 0,062 & 0,051 \\
\hline 20 & 0,096 & 0,064 & 0,120 & 0,095 & 0,124 & 0,101 \\
\hline 40 & 0,192 & 0,128 & 0,240 & 0,190 & 0,248 & 0,202 \\
\hline 60 & 0,288 & 0,192 & 0,360 & 0,284 & 0,372 & 0,303 \\
\hline 70 & 0,336 & 0,224 & 0,420 & 0,332 & 0,434 & 0,354 \\
\hline 80 & 0,384 & 0,256 & 0,480 & 0,379 & 0,496 & 0,404 \\
\hline 90 & 0,432 & 0,288 & 0,540 & 0,426 & 0,558 & 0,455 \\
\hline 100 & 0,480 & 0,320 & 0,600 & 0,474 & 0,620 & 0,506 \\
\hline
\end{tabular}
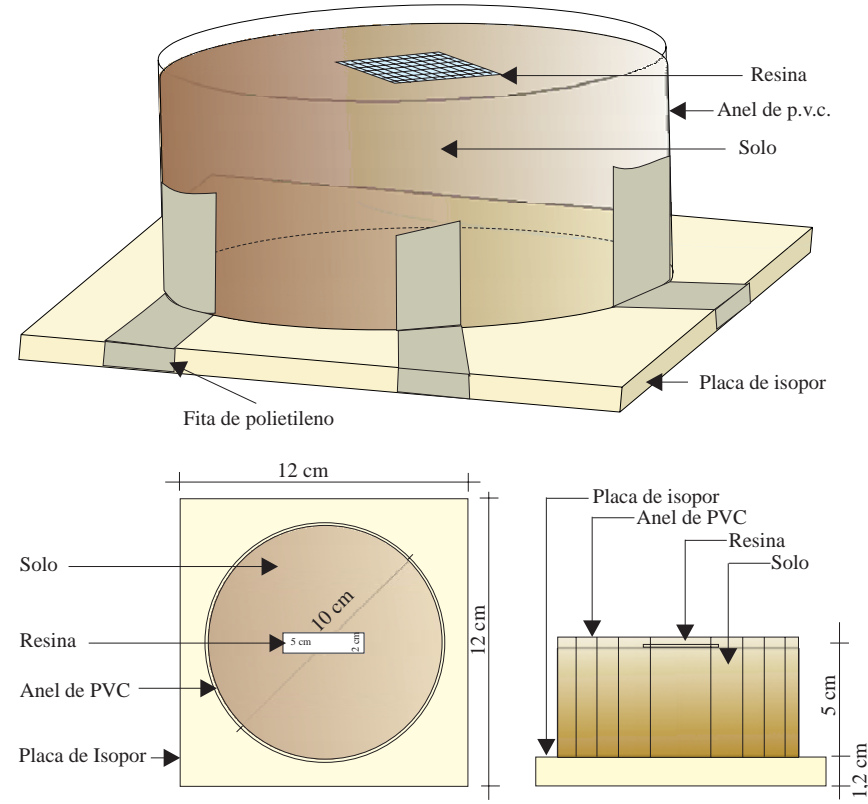

Figura 2. Esquema da câmara de difusão (anel de PVC) com a resina trocadora de cátions 
compactação; os valores de densidade foram de 1,38, 1,22 e $1,00 \mathrm{~g} \mathrm{~cm}^{-3}$ (Tabela 1) para as amostras não-compactados e $1,79,1,59$ e $1,30 \mathrm{~g} \mathrm{~cm}^{-3}$ para as amostras compactadas dos $\mathrm{LV}_{1}$, LVdf e $\mathrm{LV}_{2}$, respectivamente.

A resina catiônica utilizada como dreno de potássio para avaliação de seu fluxo difusivo, foi a fabricada pela IONICS (CR 61-CZR-442). Antes da utilização a folha de resina foi cortada em lâminas com área de $10 \mathrm{~cm}^{2}(5,0$ x 2,0 cm) e submetida a pré-condicionamento e tratamento para uso conforme Raij et al. (1987). Em virtude da compactação aplicada a resina foi disposta horizontalmente na superfície do solo.

O ensaio foi conduzido em condições de laboratório com temperatura controlada a $25 \pm 3^{\circ} \mathrm{C}$; 15 dias depois, a resina foi retirada da câmara e lavada com jatos de água para remoção do solo aderido; em seguida, o excesso de água foi absorvido por papel-filtro.

\section{Avaliação do fluxo difusivo}

O potássio adsorvido foi extraído pela agitação da membrana com $50 \mathrm{~mL}$ de uma solução de $\mathrm{NH}_{4} \mathrm{Cl} 0,8 \mathrm{~mol} \mathrm{~L}{ }^{-1}+\mathrm{HCl}$ $0,2 \mathrm{~mol} \mathrm{~L}^{-1}$ durante uma hora, em agitador horizontal a 270 rpm, utilizando-se metodologia descrita por Raij et al. (1987). A dosagem se deu por fotometria de chama, enquanto a estimativa da difusão (fluxo difusivo) foi realizada pela quantificação do potássio adsorvido às lâminas de resina, durante 15 dias.

Com base nos resultados para difusão de potássio no solo, realizaram-se análises de variância (teste F) e análises de regressão.

\section{RESULTADOS E DISCUSSÃO}

A difusão do potássio nos solos não-compactados e sob condições de compactação, aumentou quando o conteúdo de água também aumentou em todos os solos (Tabelas 3 e 4). Esses resultados são concordantes com os de Kuchenbuch et al. (1986), que constataram acréscimo de 10 vezes no coeficiente de difusão desse elemento, quando o conteúdo volumétrico de água aumentou de 0,1 para $0,4 \mathrm{~cm}^{3} \mathrm{~cm}^{-3}$; os autores atribuíram o aumento principalmente ao acréscimo no fator de impedância com o mais alto conteúdo de água. Os valores de fluxo difusivo (FD) de potássio foram maiores quando não se promoveu a compactação em todos os solos. Para Rosolém et al. (2003), independentemente da dose de potássio e do teor de água no solo, a difusão foi o principal mecanismo de transporte do nutriente no solo.

Notou-se, comparando-se os três solos não-compactados (Tabelas 3 e 4), que o LVdf atingiu o maior valor de FD $\left(63,88 \mu \mathrm{mol} \mathrm{cm} \mathrm{cm}^{-2} \mathrm{~K}\right.$ por 15 dias) no nível mais alto de umidade; já nos níveis mais baixos, a difusão foi maior no $\mathrm{LV}_{2}$; previa-se um FD maior no $L V_{1}$, em virtude deste ser mais arenoso, com menores CTC e poder tampão que os outros dois (Tabela 1). Os resultados sugerem que a menor dose de potássio aplicada neste solo pode ter contribuído para tal comportamento. A dose de potássio utilizada no $\mathrm{LV}_{2}$ correspondeu ao dobro da aplicada no LVdf, e esta foi duas vezes
Tabela 3. Fluxo difusivo de potássio influenciado por níveis de umidade e por níveis de compactação nos solos estudados

\begin{tabular}{|c|c|c|c|c|c|c|}
\hline \multirow{3}{*}{$\begin{array}{c}\text { Nível de } \\
\text { umidade }^{1 /} \\
\%\end{array}$} & \multicolumn{2}{|c|}{$\mathrm{LV}_{1}$} & \multicolumn{2}{|c|}{$L V_{d f}$} & \multicolumn{2}{|c|}{$\mathrm{LV}_{2}$} \\
\hline & $1^{2 /}$ & $2^{3 /}$ & $1^{2 /}$ & $2^{3 /}$ & $1^{2 /}$ & $2^{3 /}$ \\
\hline & \multicolumn{6}{|c|}{$\mu \mathrm{mol} \mathrm{cm}-2 \mathrm{~K} / 15$ dias } \\
\hline 10 & 5,53 & 3,09 & 6,56 & 3,08 & 14,83 & 11,21 \\
\hline 20 & 9,90 & 7,64 & 17,92 & 6,40 & 29,44 & 19,52 \\
\hline 40 & 24,66 & 14,05 & 35,87 & 8,93 & 38,93 & 27,20 \\
\hline 60 & 28,75 & 15,57 & 46,47 & 15,00 & 44,96 & 36,40 \\
\hline 70 & 47,14 & 18,40 & 55,84 & 30,25 & 50,02 & 39,81 \\
\hline 80 & 51,54 & 24,94 & 58,86 & 38,64 & 54,52 & 42,61 \\
\hline 90 & 60,57 & 27,83 & 62,71 & 50,07 & 57,73 & 47,07 \\
\hline 10 & 55,47 & 32,65 & 63,88 & 50,65 & 59,49 & 50,01 \\
\hline
\end{tabular}

1/ Fração da porosidade total das amostras dos solos, ocupada com água; ${ }^{2 /}$ Condições de densidade natural; ${ }^{3 /}$ Compactado

Tabela 4. Equações de regressão relacionando o fluxo difusivo de potássio (FD) com os conteúdos de água $(\mathrm{X})$ nos níveis de compactação, em cada um dos solos utilizados

\begin{tabular}{|c|c|c|c|}
\hline Solo & $\begin{array}{c}\text { Nível de } \\
\text { compactação }\end{array}$ & Equação & $\mathbf{R}^{2}$ \\
\hline \multirow[t]{2}{*}{$\mathrm{LV}_{1}$} & $1^{1 /}$ & $F D=-1,641+131,516^{\star \star x} X$ & 0,951 \\
\hline & $2^{2 /}$ & $F D=0,265+94,443^{* * X}$ & 0,962 \\
\hline \multirow[t]{2}{*}{$\mathrm{LV}_{\mathrm{df}}$} & $1^{1 /}$ & $F D=-4,42+198,86^{\star \star} X-140,05^{\star \star} X^{2}$ & 0,997 \\
\hline & $2^{2 /}$ & $F D=-8,112+120,311^{\star * x} X$ & 0,906 \\
\hline \multirow[t]{2}{*}{$\mathrm{LV}_{2}$} & $1^{1 /}$ & $F D=10,50+129,26 * \star X-82,093^{*} X^{2}$ & 0,977 \\
\hline & $2^{2 /}$ & $F D=9,760+82,402^{\star *} X$ & 0,988 \\
\hline
\end{tabular}

1/ Condições de densidade natural; ${ }^{2 /}$ Compactado; */ Significativo a 1\%; **/ Significativo a 5\%

maior que a dose usada no $\mathrm{LV}_{1}$; referidas doses foram aplicadas em função da CTC; não se verificou presença de minerais do tipo 2:1 na fração argila dos solos (Figura 1); assim, não é esperada a fixação de potássio nesses solos.

A diferença no FD entre os solos pode ser atribuída às maiores doses de potássio utilizadas nos solos mais argilosos. Os resultados estão de acordo com os do trabalho de Baligar (1984b) que, estudando o coeficiente de difusão como variável da concentração de $\mathrm{K}$, Ca e Mg, encontrou maior coeficiente de difusão de potássio em um solo com maior teor de argila e CTC, em relação a outros dois. Altas concentrações de um cátion na solução do solo reduzem a sua capacidade tampão (Baligar, 1985).

Segundo Novais \& Smyth (1999), a necessidade de medidas do fator capacidade como critério de interpretação do “disponível”, como utilizado para fósforo, não se aplica para potássio, não necessitando de uma medida de Fator Capacidade de K no solo (FCK) o que, aliado à aplicação de maiores doses de $\mathrm{K}$ nos solos mais argilosos, pode explicar os maiores valores de FD desses solos em relação ao $\mathrm{LV}_{1}$. Neste trabalho, as doses de potássio utilizadas foram muito altas, como já referido mas, mesmo assim, houve acentuada diferença no FD em função dos níveis de umidade, da compactação e dos solos usados.

Vários trabalhos se referem ao aumento do coeficiente de difusão de cátions no solo com o aumento de sua concentração (Baligar \& Barber, 1978; Melo et al., 2005; Freitas et al., 2007). Trabalhando com resina de troca catiônica, Baligar 
(1984a) constatou a grande influência da concentração de potássio no solo, no processo difusivo deste elemento.

O FD aumentou com o acréscimo do conteúdo de água em todos os solos. A elevação do conteúdo de água no solo reduz a tortuosidade do caminho da difusão, aumentando a espessura do filme de água no interior dos poros. A umidade pode, também, influenciar a distribuição de íons entre as fases sólida e líquida do solo. Nye \& Tinker (1977), relacionando o fator de impedância (f) e a umidade do solo, verificaram que, em solo muito seco, $\mathrm{f}$ apresentou valores muito baixos (2 x 10-4 a um potencial matricial de $-10 \mathrm{MPa}$, e $10^{-2}$ a -1,5 MPa). Quando os potenciais estiveram entre -0,1 e -1,0 MPa, o fator de impedância aumentou linearmente com o conteúdo de água. Segundo os autores, o fator de impedância se aproxima de zero nos solos mais secos atingindo valores entre 0,4 e 0,7 em condições de saturação.

Nos níveis mais baixos de umidade o FD foi menor que nos mais elevados mas, mesmo assim, com valores expressivos quando se considera que, no menor nível de umidade, a água aplicada correspondeu a um conteúdo volumétrico muito baixo para os três solos, o que pode encontrar explicação nas doses elevadas de potássio aplicadas.

As diferenças nos valores de FD em razão da compactação foram mais pronunciadas entre os níveis de umidade mais baixos, em todos os solos; quando se comparam o menor e o maior nível de umidade se registram acréscimos no FD, de 10,03, 9,73 e 4,01 vezes nos $L V_{1}$, $L V d f$ e $L V_{2}$, respectivamente; tais aumentos indicam a importância da água no processo de difusão do elemento dentro de cada solo. Observa-se que, embora o $\mathrm{LV}_{1}$ tenha apresentado menores valores de FD que os outros dois solos, o acréscimo entre o maior e o menor nível de umidade foi maior naquele solo, ou seja, o FD de potássio seria mais afetado em solos mais arenosos quando secos do que nos argilosos.

As equações de regressão que relacionam o FD de potássio com os conteúdos de água nos três solos (Tabela 4) foram lineares para o $\mathrm{LV}_{1}$ e quadráticas para o $\mathrm{LVdf}$ e o $L V_{2}$, não se verificando a relação direta, linear, como previsto na equação de difusão, entre o conteúdo volumétrico de água do solo e o coeficiente de difusão, para esses dois últimos solos.

Quando se promoveu a compactação dos solos (Tabelas 3 e 4), o FD de potássio também aumentou em todos os solos com o acréscimo do conteúdo de água, como ocorreu com os solos não-compactados, sendo a magnitude deste FD menor em todos os tratamentos. Os valores de FD de potássio diminuíram em todos os níveis de umidade e nos três solos, quando se promoveu a compactação em relação aos solos nãocompactados. As alterações no FD de um íon quando um solo é submetido a compactação, aumentando-se a densidade aparente, são atribuídas a mudanças no fator de impedância. Comparando-se as condições de não-compactado e compactado, verificam-se menores diferenças no FD do que quando se comparam o menor e o maior nível de umidade em todos os solos, mostrando que a umidade influenciou mais o FD que a compactação. So \& Nye (1989), utilizando cloro para medir o fator de impedância, verificaram que a umidade exercia efeito muito mais pronunciado na difusão do elemen- to do que a densidade do solo. Os modelos ajustados foram lineares nos três solos sob compactação, indicando a proporcionalidade entre o conteúdo volumétrico de água do solo e o coeficiente de difusão.

Comparando-se os três solos sob condições de compactação, tem-se que o menor valor do FD ocorreu no $L_{1}$ $\left(32,65 \mu \mathrm{mol} \mathrm{cm} \mathrm{cm}^{-2} \mathrm{~K}\right.$ por 15 dias $)$ e o maior no $L_{2}$ (50,65 $\mu \mathrm{mol} \mathrm{cm} \mathrm{cm}^{-2} \mathrm{~K}$ por 15 dias), que foi praticamente o mesmo do LVdf $\left(50,01 \mu \mathrm{mol} \mathrm{cm} \mathrm{cm}^{-2} \mathrm{~K}\right.$ por 15 dias $)$ para o nível mais alto de umidade; a diferença entre os solos, além da utilização de doses de potássio diferentes, pode estar na quantidade de água aplicada, já que o $L V_{1}$ recebeu menos água que o $L V d f$ e o $L_{2}$. As relações entre os maiores e os menores valores de FD, que ocorreram com os mais elevados e os mais baixos conteúdos volumétricos de água, foram de 10,57; 16,44 e 4,46 para os $L V_{1}$, $L V d f$ e $L_{2}$, respectivamente; dito acréscimo do FD nos três solos, quando se aumentou o conteúdo de água no solo, mostrou a importância da água no processo difusivo do potássio no solo, em condições de compactação. Oliveira et al. (2004) se referem à maior difusão de potássio quando o solo está bem suprido deste elemento.

O efeito da compactação na difusão é contraditório, segundo dados encontrados na literatura. Nye \& Tinker (1977) mostram resultados em que o coeficiente de difusão de rubídio aumentou em torno de três vezes quando um solo arenoso foi compactado, tendo a sua densidade aparente aumentada de 1,36 para 1,95 g cm³; já Warncke \& Barber (1972b) encontraram, para cloro, valores de difusão menores quando se elevou a densidade aparente de 1,3 para $1,6 \mathrm{~g} \mathrm{~cm}^{-3}$. O coeficiente de difusão de estrôncio aumentou cerca de $50 \%$ e o de rubídio diminuiu em torno de $20 \%$, com o aumento da densidade aparente do solo de 1,3 para $1,8 \mathrm{~g} \mathrm{~cm}^{-3}$.

Neste trabalho, os menores valores de FD foram encontrados nos níveis de umidade mais baixos e em condições de densidade aparente mais elevada, o que está de acordo com Mullins \& Edwards (1987), os quais verificaram coeficientes de difusão de cátions no solo, diminuindo com o aumento da densidade, sendo os efeitos mais pronunciados em conteúdos de água mais baixos. Dados de Medeiros et al. (2005) também ratificam os resultados.

A continuidade dos filmes de água pode ser mais afetada pelo acréscimo da densidade a baixos conteúdos de água, quando comparados com conteúdos mais altos. Os efeitos da densidade foram relativamente menores quando comparados com os efeitos do conteúdo de água e da dose do elemento.

É comum encontrar, na literatura, trabalhos mostrando que o acréscimo da densidade aparente aumenta o coeficiente de difusão, quando a mesma quantidade de água é aplicada nas duas condições: antes e após a compactação. De acordo com Barber (1995), a densidade aparente exerce grande efeito sobre o fator de impedância em altos níveis de umidade, em virtude da diminuição do espaço poroso ocupado pelo ar, permitindo maior continuidade da água, como conseqüência do aumento da densidade aparente. Neste trabalho, os conteúdos de água nos solos compactados foram aplicados de acordo com a nova porosidade que os solos apresentaram após a compactação (Tabela 2). 
Pelos dados deste trabalho observou-se que, a despeito das elevadas doses de potássio utilizadas, ainda assim houve forte influência dos níveis de umidade e de compactação no FD de potássio, nos solos estudados.

\section{CONCLUSÕES}

1. O fluxo difusivo de potássio no solo foi influenciado pela umidade e pela compactação do solo, aumentando com o acréscimo do conteúdo de água e apresentando valores mais baixos na condição de solo com elevada densidade.

2. Ocorreu relação direta linear entre o conteúdo volumétrico de água no solo e a difusão de potássio no solo, na condição de solo com elevada densidade.

3. Nos solos sem compactação, relação direta e linear entre fluxo difusivo de potássio no solo e umidade do solo, foi verificada apenas no solo de textura mais arenosa.

\section{LITERATURA CITADA}

Baligar, V. C. Effective diffusion coefficient of cations as influenced by physical and chemical properties of selected Indiana soils. Communications in Soil Science and Plant Analysis, v.15, p.1367-1376, 1984a.

Baligar, V. C. Potassium additions on ionic equilibria, selectivity and diffusion of cations in soils. Communications in Soil Science and Plant Analysis, v.15, p.1351-1365, 1984b.

Baligar, V. C. Influence of crop growth on ionic equilibria, selectivity and diffusion of cations in soil. Communications in Soil Science and Plant Analysis, v.16, p.163-178, 1985.

Baligar, V. C.; Barber, S. A. Use of K/Rb ratio to characterize potassium uptake by plant roots growing in soil. Soil Science Society of America Journal, v.42, p.575-579, 1978.

Barber, S. A. Influence of the plant root on ion movement in soil. In: Carson, E. W., ed. The plant root and its environment. Charlottesville: University Press of Virginia, 1974. p.525-564.

Barber, S. A. Soil nutrient bioavailability: A mechanistic approach. New York: John Wiley \& Sons, 1995. 414p.

Beutler, A. N.; Centurion, J. F.; Centurion, M. A. P. C.; Silva, A. P. Efeito da compactação na produtividade de cultivares de soja em Latossolo Vermelho. Revista Brasileira de Ciência do Solo, v.28, p.787-794, 2006.

Bortoluzzi, E. C.; Santos, D. R.; Kaminski, J.; Gatiboni, L. C.; Tessier, D. Alterações na mineralogia de um argissolo do Rio Grande do Sul submetida à fertilização potássica. Revista Brasileira de Ciência do Solo, v.29, p.327-335, 2005.

Defelipo, B. V.; Ribeiro, A. C. Análise química do solo (metodologia). Viçosa: UFV, 1981. 17p. Boletim de Extensão, 29

EMBRAPA - Empresa Brasileira de Pesquisa Agropecuária. Serviço Nacional de Levantamento e Conservação de Solos. Manual de métodos de análise de solo. 2. ed. Rio de Janeiro: Embrapa-SNLCS, 1997. 212p.

EMBRAPA - Empresa Brasileira de Pesquisa Agropecuária. Sistema Brasileiro de Classificação de Solo. Rio de Janeiro: Embrapa-CNPS, 1999. 412p.
Fernandes, B. Retenção e movimento de água no solo. Viçosa: UFV, 1967. 49p. Dissertação Mestrado

Fernandes, M. S. Nutrição mineral de plantas. Viçosa: Sociedade Brasileira de Ciência do Solo, 2006. 432p.

Freitas, R. J.; Leandro, W. M.; Carvalho, M. C. S. Efeito da adubação potássica via solo e foliar sobre a produção e a qualidade da fibra em algodoeiro (Gossypium hirsutum L.). Pesquisa Agropecuária Tropical, v.37, p.106-112, 2007.

Jackson, M. L. Soil chemical analysis. New Jersey: Prentice-Hall, 1958. 498p.

Kuchenbuch, R.; Claassen, N.; Jung K, A. Potassium availability in relation to soil moisture. I. Effect of soil moisture on potassium uptake of onion plants. Plant and Soil, v.95, p.221-231, 1986.

Lopes, A. S. Solos sob “cerrado": características, propriedades e manejo. Piracicaba: Associação Brasileira para Pesquisa da Potassa e do Fosfato, 1984. 162p.

Medeiros, R. D.; Soares, A. A.; Guimarães, R. M. Compactação do solo e manejo da água. I: Efeitos sobre a absorção de N, P, $\mathrm{K}$, massa seca de raízes e parte aérea de plantas de arroz. Ciência e Agrotecnologia, v.29, p.940-947, 2005.

Mehta, B. K.; Shiozawa, S.; Nakano, M. Measurement of molecular diffusion of salt in unsaturated soils. Soil Science, v.159, p.115-121, 1995.

Melo, V. F.; Correa, G. F.; Ribeiro, A. N.; Maschio, P. A. Cinética de liberação de potássio e magnésio pelos minerais da fração argila de solos do triângulo mineiro. Revista Brasileira de Ciência do Solo, v.29, p.533-545, 2005.

Mullins, G. L.; Edwards, J. H. Effect of fertilizer amendments, bulk density and moisture on calcium and magnesium diffusion. Soil Science Society of America Journal, v.51, p.12191224, 1987.

Novais, R. F.; Smyth, T. J. Fósforo em solo e planta sob condições tropicais. Viçosa: UFV, 1999. 399p.

Nye, P. H.; Tinker, P. B. Solute movement in the soil-root system. Berkeley: University of California Press, 1977. 342p.

Oliveira, R. H.; Rosolém, C. A.; Trigueiro, R. M. Importância do fluxo de massa e difusão no suprimento de potássio ao algodoeiro como variável de água e potássio no solo. Revista Brasileira de Ciência do Solo, v.28, p.439-445, 2004.

Raij, B. van; Quaggio, J. A.; Cantarella, H.; Ferreira, M. E.; Lopes, A. S; Bataglia, O. C. Análise química do solo para fins de fertilidade. Campinas: Fundação Cargill, 1987. 170p.

Ritchey, K. D. O potássio nos oxissolos e ultissolos dos trópicos úmidos. Piracicaba: Instituto da Potassa e Fosfato, Instituto Internacional da Potassa, 1982. 69p. Boletim Técnico, 7

Rosolém, C. A.; Mateus, G. P.; Godoy, L. J. G.; Feltran, J. C.; Brancalião, S. R. Morfologia radicular e suprimento de potássio às raízes de milheto de acordo com a disponibilidade de água e potássio. Revista Brasileira de Ciência do Solo, v.27, p.875-884, 2003.

Ruiz, H. A.; Miranda, J.; Conceição, J. C. S. Contribution of mass flow and diffusion mechanisms for supplying $\mathrm{K}$, Ca and Mg to rice plants. Revista Brasileira de Ciência do Solo, v.23, p.1015-1018, 1999.

So, H. B.; Nye, P. H. The effect of bulk density, water content and soil type on the diffusion of chloride in soil. Journal of Soil Science, v.40, p.743-750, 1989. 
Tisdale, S. L.; Nelson, W. L. Soil fertility and fertilizers. New York: Macmillan Publishing, 1975. 694p.

Vargas, R. M. B. Mecanismos de suprimento de K, Ca, Mg e P às raízes de milho em solos do Rio Grande do Sul. Porto Alegre: UFRGS, 1982. 93p. Tese Doutorado

Vettori, L. Métodos de análises de solo. Equipe de pedologia e fertilidade do solo. Rio de Janeiro: Ministério da Agricultura, 1969. 24p. Boletim Técnico, 7

Villani, E. M. A. Fluxo difusivo de fósforo influenciado por fontes e por tempo de contato do fósforo com o solo. Viçosa: UFV, 1995. 57p. Dissertação Mestrado
Warncke, D. D.; Barber, S. A. Diffusion of zinc in soil: I. The influence of soil moisture. Soil Science Society of America Proceedings, v.36, p.39-42, 1972a.

Warncke, D. D.; Barber, S. A. Diffusion of Zn in soils: II. The influence of soil bulk density and its interaction with soil moisture. Soil Science Society of America Proceedings, v.36, p.4246, $1972 b$.

Wild, A. Mass flow and diffusion. In: Greenland, D. J.; Hayes, M. H. B. eds. The chemistry of soil processes. Chichester: John Wiley and Sons, 1981. p.37-80. 